\title{
SISTEM MONITORING PENGERING SEPATU BERBASIS INTERNET OF THINGS PADA PLATFORM NODE-RED
}

Yuli Murdianingsih ${ }^{* 1}$, Lina Aprianti ${ }^{\# 2}$

\author{
Program Studi Teknik Informatika,STMIK Subang ${ }^{* 1 \# 2}$ \\ E-mail: yuli_murdianingsih@yahoo.com ${ }^{* 1}$, lyna.aprianti@gmail.com ${ }^{\# 2}$
}

\begin{abstract}
Abstrak
Pengeringan sepatu secara konvensional masih berrgantung pada bantuan sinar matahari dalam pengeringan. Sepatu merupakan salah satu perlengkapan manusia yang harus selalu dipakai dalam kondisi, termasuk saat musim penghujan. Penelitian ini bertujuan untuk membangun sistem monitoring pengering sepatu berbasis Internet of Things Pada Platform Node-red. dilakukan memonitoring cahaya, suhu serta kelembaban pada sepatu. Perangkat keras yang diperlukan untuk membangun sistem ini yaitu Arduino Uno, NodeMC ESP8266, Breadboard, Kabel Jumper (male-to-male, male-to-female, female-to-female), Kabel USB Arduino, Relay 2 Channel, Lampu Pijar, Kipas CPU, Motor Servo, Sensor DHT11 dan Sensor LDR. Sedangkan perangkat lunak yang digunakan yaitu Arduino IDE, berperan sebagai tempat penulis memprogram NodeMCU ESP8266, Arduino Uno, dan komponen hardware lainnya agar bisa dipakai dalam penelitian ini. Program editor dan compiler bahasa C untuk membuat program. Platform Node-red dibutuhkan sebagai komponen utama pada penerapan penelitian ini. Sistem monitoring pengering sepatu ini menggunakan arsitektur jaringan Wireless dan menggunakan NodeMCU ESP8266 sebagai alat yang digunakan. Hasil dari penelitian ini yaitu sistem monitoring pengering sepatu ini mampu berfungsi dengan baik sesuai dengan apa yang diharapkan, alat ini mampu memonitoring cahaya, suhu serta kelembaban pada sepatu secara real time, termasuk dapat memberikan aksi berupa notifikasi melalui media sosial berupa Telegram.
\end{abstract}

Kata kunci: Sistem pengeringan sepatu, IoT, Node-Red.

\begin{abstract}
Shoes are one of the human equipment that must always be worn in conditions, including during the rainy season, and conventional shoe drying still faces several challenges, including relying on the help of sunlight to facilitate drying. Shoes are one of the human equipment that must always be worn in conditions, including during the rainy season. The goal of this research is to create a shoe dryer monitoring system using the Node-ed Platform and the Internet of Things. Light, temperature, and humidity are all monitored in shoes. Arduino Uno, NodeMC ESP8266, Breadboard, Jumper Cables (male-to-male, male-to-female, female-to-female), Arduino USB Cable, 2 Channel Relay, Incandescent Lamp, CPU Fan, Servo Motor, DHT11 Sensor, and LDR Sensor are the components needed to make this system. While the software, specifically Ardu, was used, While the software employed, specifically the Arduino IDE, allows the author to program the NodeMCU ESP8266, Arduino Uno, and other hardware components that will be used in this study. To write programs, you'll need a $C$ program editor and compiler. The major component in the implementation of this research is the Node-red platform. The NodeMCU ESP8266 is used as a tool in this shoe dryer monitoring system, which leverages a wireless network architecture. The shoe dryer monitoring system can perform as intended as a result of this research; this tool can monitor light, temperature, and humidity in shoes in real-time, as well as deliver actions in the form of notifications via social media in the form of Telegram.
\end{abstract}

\section{Kata kunci: Shoe drying system, IoT, Node-Red.}

\section{Pendahuluan}

Snake care subang merupakan salah satu tempat pengeringan sepatu. Dalam kenyataannya, terkadang snake care subang mengalami kesulitan dalam proses pengeringan. Kesulitan yang dihadapi selama ini terutama pada musim hujan dan pada saat ada permintaan dari konsumen untuk pengeringan yang lebih cepat karena proses pengeringannya masih dilakukan dengan cara konvensional menggunakan bantuan sinar matahari.

Melihat permasalahan tersebut, diperlukan nya sebuah solusi untuk memecahkan nya. Maka, 
perlu dibuatkan sebuah sistem untuk mengeringkan sepatu tanpa bergantung pada bantuan sinar matahari. Sehingga, sistem pengering sepatu tersebut bisa digunakan sewaktu-waktu, kapanpun dan dimanapun dengan waktu yang relatif lebih cepat serta meminimalisir terjadinya dampak dan penyakit seperti menimbulkan bau tidak sedap, penyakit kaki, sepatu berjamur serta kerusakan pada bahan maupun warna yang diakibatkan oleh proses penjemuran yang terlalu lama.

penelitian oleh [1]menghasilkan desain jemuran otomatis yang dilengkapi dengan sensor cahaya, sensor air dan juga dilengkapi dengan sensor kelembaban untuk mengukur tingkat kekeringan pakaian, kita tidak perlu khawatir tentang pakaian yang berada dijemuran karena sudah dilindungi dengan sistem jemuran otomatis dimana atap jemuran akan otomatis menutup dikala cuaca dalam keadaan mendung ataupun saat turun hujan.

Prototype jemuran pakaian otomatis untuk membantu masalah-masalah yang terjadi pada saat cuaca tidak menentu, karena jemuran ini bekerja keluar dan masuk otomatis sesuai dengan sensor yang digunakan pada alat, saat pakaian sudah kering, sensor wire akan mendeteksi intensitas air pada pakaian kemudian jemuran masuk kedalam tanpa harus menunggu sore atau malam, sedangkan apabila jemuran masuk dalam keadaan basah maka output seperti heater dan fan akan aktif sebagai pengering alternatif[2].

Penelitian oleh [3] menghasilkan jemuran pakaian pintar berbasis Internet of Things, menggunakan mikrokontroler Arduino Nano sebagai pengendali dan nodemcu sebagai alat mengirimkan data ke-database atau server yang nantinya data-data tersebut dapat dimonitoring dari website, sebagai input alat ini menggunakan sensor cahaya (Light Dependent Resistor), sensor air, sensor suhu dan kelembaban (DHT22) dan limit switch, sedangkan output ada buzzer untuk indikator aktifitas.

Penelitian [4] menghasilkan mesin pengering sepatu dengan kompor sebagai sumber panas, mesin tersebut dikontrol oleh arduino dengan input berupa tombol dan sensor kelembaban, output pada arduino tersebut yaitu sinar ultraviloet, pengharum sepatu dan kompor, mesin pengering tersebut tidak hanya untuk mengeringkan sepatu tetapi kaharuman dari sepatu tersebut dapat terjaga.

Dalam pennelitian ini penulis akan mengoptimalkan monitoring pengering seopatu menggunakan sistem Internet of Things (IoT). Penelitian ini bertujuan untuk membangun sistem monitoring pengering sepatu berbasis Internet of Things Pada Platform Node-red. IoT merupakan teknologi yang memungkinkan adanya pengendalian, komunikasi, kerja sama dengan berbagai perangkat keras, berbagai data, memvirtualisasikan segala hal nyata ke dalam bentuk internet, dan lain-lain melalui jaringan internet, IoT juga dapat digunakan untuk hal lain seperti pengambilan data dari suatu tempat dengan menggunakan sensor dan juga akses jarak jauh untuk mengendalikan benda lain di suatu tempat, IoT bisa diterapkan di berbagai sistem atau alat salah satunya pada Sistem Monitoring Pengering Sepatu berbasis IoT dimana di dalam sistem tersebut terdapat Sensor DHT 11 untuk mendeteksi Suhu dan Kelembaban serta Sensor LDR untuk mendeteksi Cahaya.

\section{Analisa dan Pembahasan}

Sistem monitoring pengering sepatu ini terdiri dari 6 aktor, yaitu user sebagai pengguna alat/sistem, mikrokontroler sebagai komponen alat, telegram sebagai sosial media yang dipakai perantara untuk notifikasi data sensor, platform (node-red) sebagai tempat untuk menerima dan menampilkan data secara IoT, mysql sebagai database server penyimpan data yang sebelumnya dikirim oleh node MCU ke platform. Dan ada empat belas use case yang terbentuk diantaranya: baca sensor dht 11, baca sensor ldr, ambil data sensor, kirim data sensor, terima data sensor, menampilkan data sensor, login, mengelola platform, simpan data sensor, registrasi no, notifikasi data sensor, ambil data, analisis data dan view hasil analisis. Berikut tampilan diagramnya seperti pada Gambar 1.. 


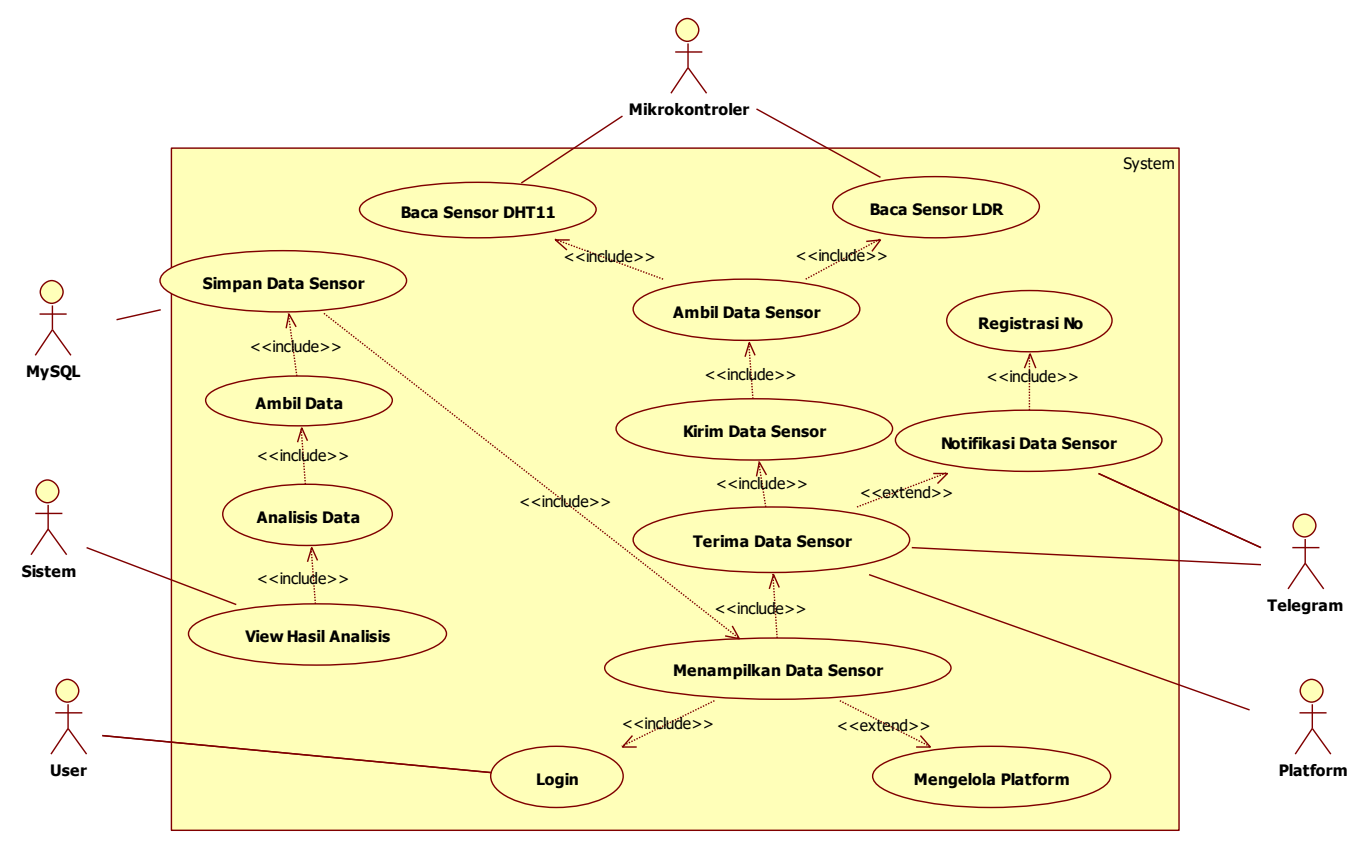

Gambar 1 Model fungsional sistem

Pada Gambar 2 merupakan rancangan alat dan sensor untuk membuat sistem monitoring pengering sepatu dengan menggunakan aplikasi Fritzing.Pada gambar tersebut terdapat beberapa komponen alat untuk membuat sistem monitoring pengering sepatu seperti arduino uno, 2 nodemcu untuk nodered dan telegram, 1 papan breadboard, relay 2 channel, sensor dht11, sensor ldr, kabel jumper female to female, male to male dan male to female. Dengan output berupa 2 servo untuk menggerakan atap secara otomatis, lampu pijar dan kipas cpu.

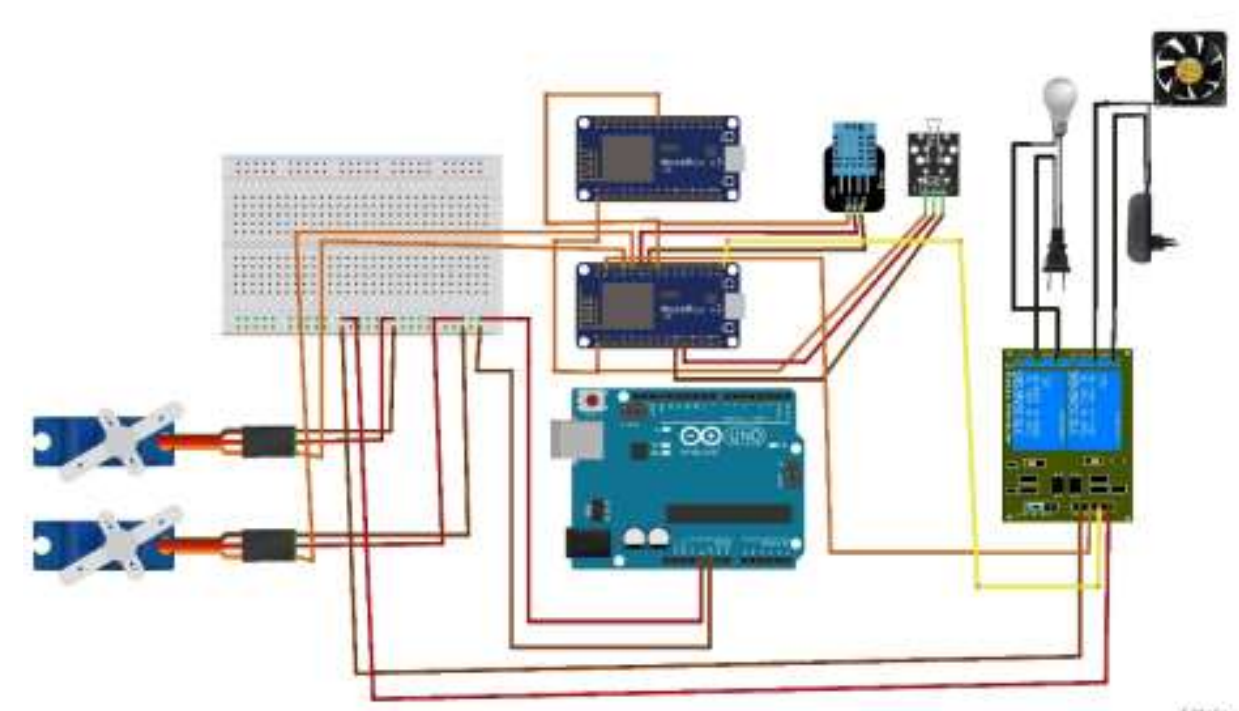

Gambar 2 Rancangan alat dan sensor

Berikutya adalah rancangan Flow node-red, dimana Flow node-red adalah alur kerja dari sebuah sistem yang dibuat di dalam platform node-red, dimana didalamnya terdapat nodes input, output dan function. Seperti pada Gambar 3. 


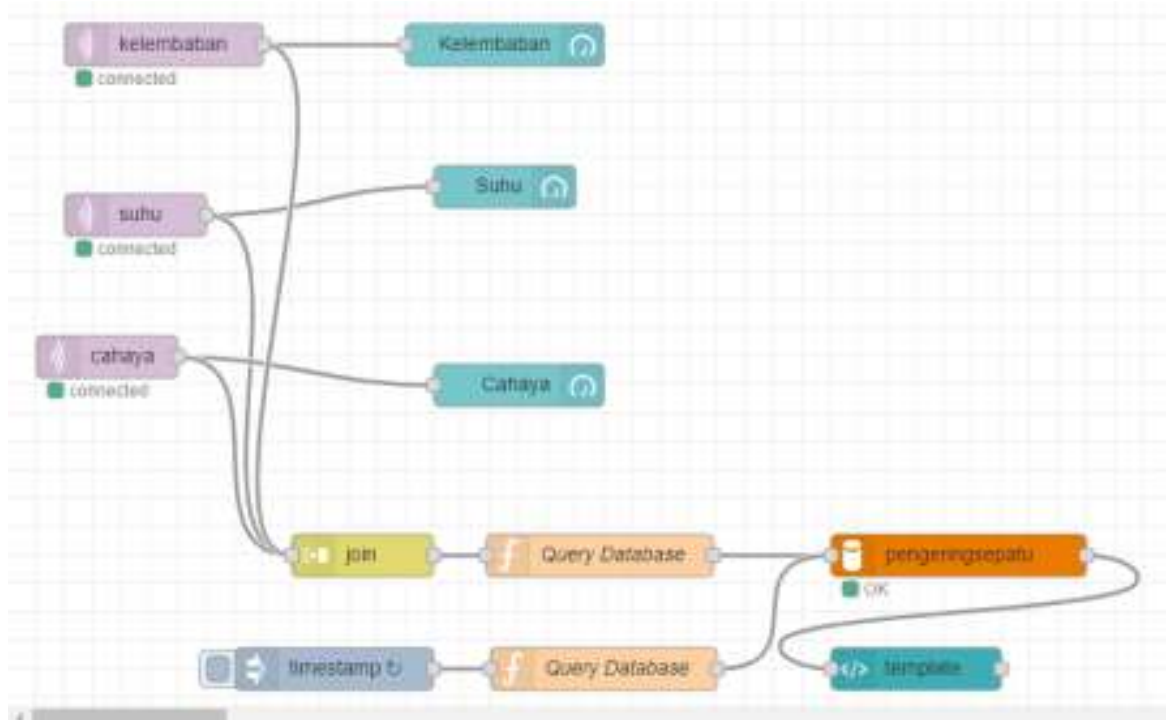

Gambar 3 Flow node-red

\section{Hasil}

Pemrograman alat atau mikrokontroler, menggunakan software arduino IDE diperlihatkan dalam Gambar 4. Sedangkan implementasi pemrograman alat dan notifikasi ke telegram yang ditunjukan pada Gambar 5.

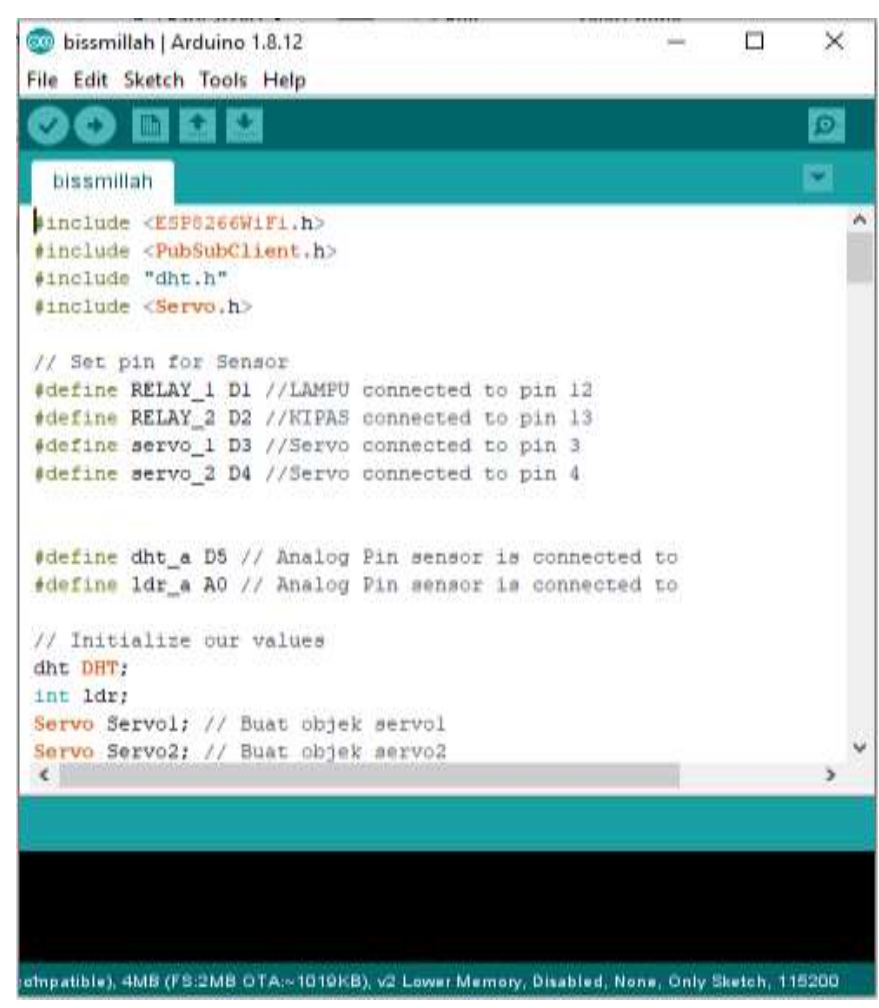

Gambar 4 Script pemrograman alat 


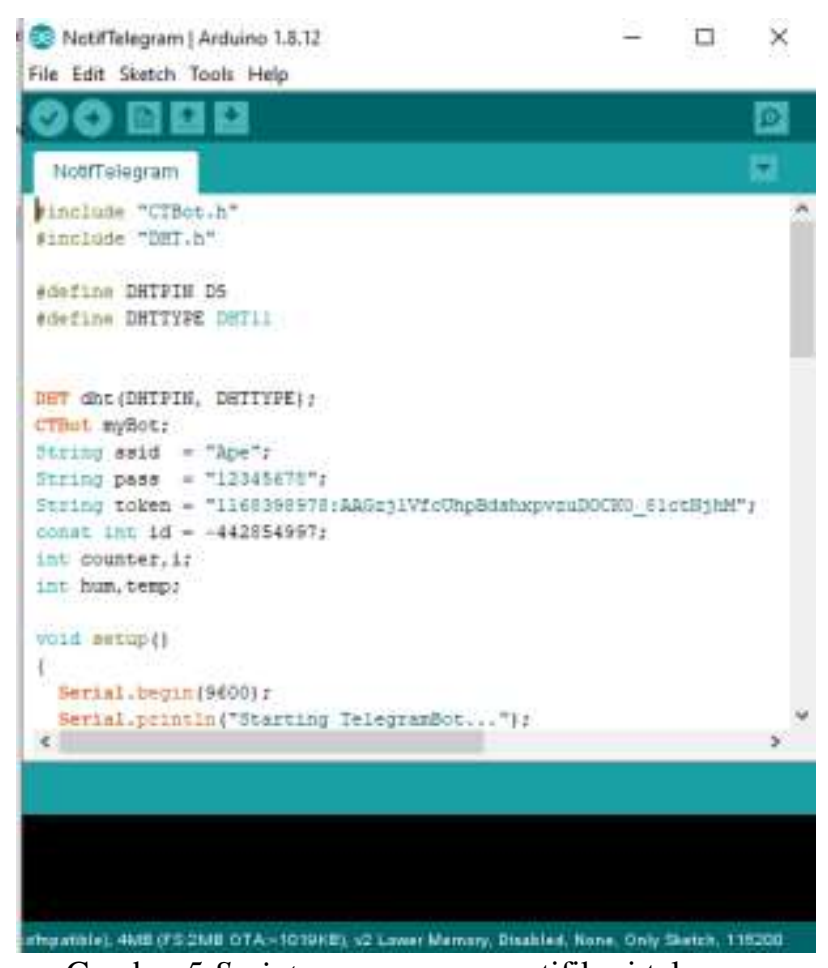

Gambar 5 Script pemrograman notifikasi telegram

Implementasi perakitan alat merupakan hasil dari perancangan alat berbentuk prototype yang sebelumnya sudah dibuat gambarannya.implementasi prototype system pengering sepatu dalam penelitian ini diperlihatkan dalam Gambar 6.

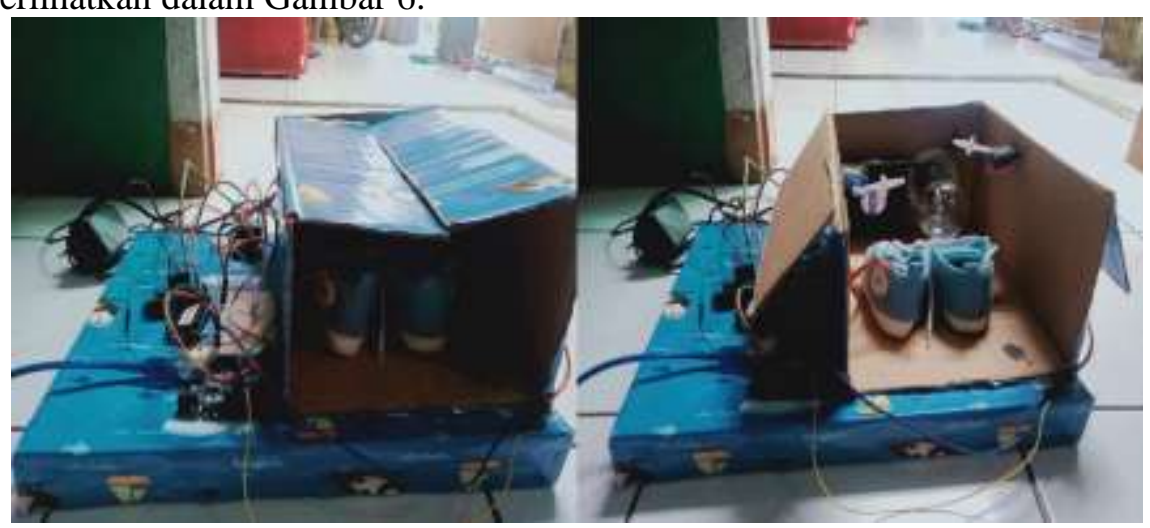

Gambar 6 Tampilan prototype pengering sepatu

Prototype dibuat dengan bahan-bahan sederhana dengan dilengkapi alat-alat mikrokontroler lainnya. Setelah prototype sistem monitoring pengering sepatu dapat diimplementasikan penulis mengaktivasi koneksi sistem kepada platform NodeRed. Hasil monitoring melalui masing-masing sensor yang ada diperlihatkan dlam Gambar 7. 


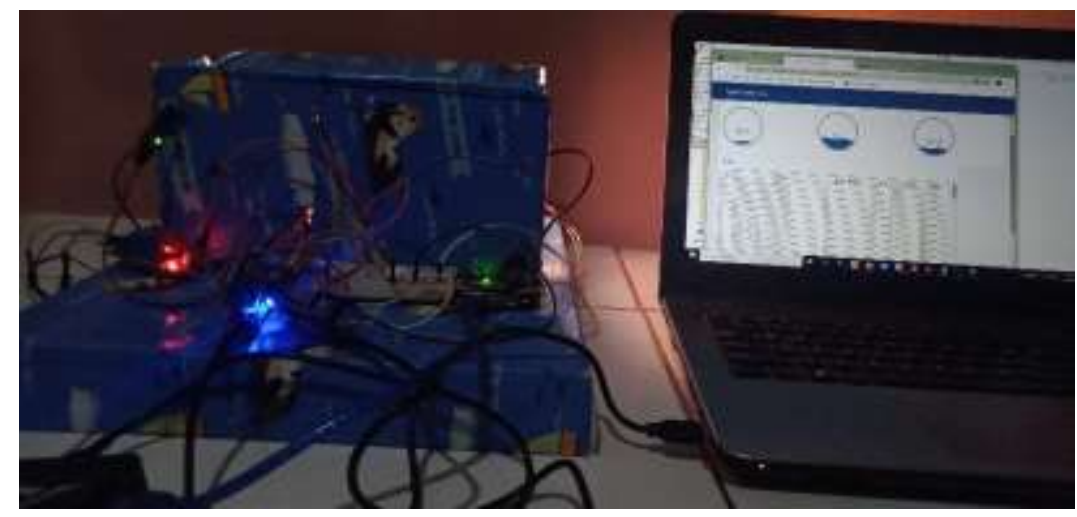

Gambar 7 Pengujian alat dalam ruangan

Pada Gambar 8 menunjukan proses pengeringan sepatu di dalam ruangan. Dimana ruangan tersebut tidak mendeteksi adanya sinar matahari, maka dari itu, atap akan tertutup serta lampu dan kipas menyala karena keadaan sepatu yang basah. Kipas dan lampu akan mati secara otomatis pada saat sepatu dalam kondisi kering.

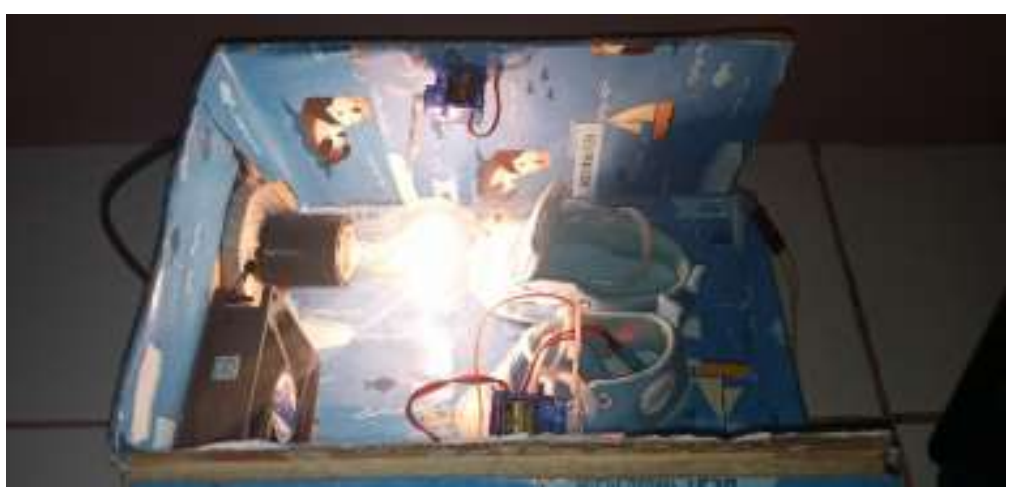

Gambar 8 Tampilan dalam Prototype

Penulis menggunakan sosial media telegram sebagai alat perantara notifikasi bahwa sepatu sudah kering. Cara kerja telegram ini yaitu admin membuat sebuah grup telegram yang saat ini hanya berisikan admin sebagai anggota dari grup. Namun, ke depannya admin bisa menambahkan konsumen snake care subang sebagai anggota grup. Informasi dan nama grup dapat ditujukan pada Gambar 9. 


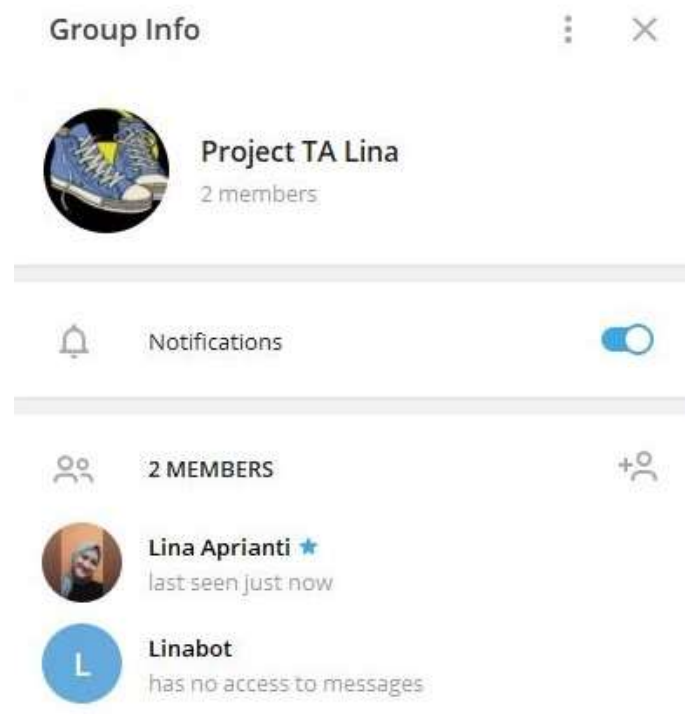

Gambar 9 Informasi grup

\section{Kesimpulan}

Penelitian ini bertujuan untuk membangun sistem monitoring pengering sepatu berbasis Internet of Things Pada Platform Node-red. Telah diperoleh system yang masih bersifrt prototype system pengeringan sepatu berbasis IoT pada platform Node-Red. System dapat memonitor suhu, kelembaban dan intensitas cahaya dan waktu pengeringan sepatu. Data hasil akuisisi sensor melalui mikrokontroler dikirm ke Platform Nod-Red untuk disajikan menjadi informasi monitoring pengeringan sepatu secara real time.

\section{Daftar Pustaka}

[1] A. D. Darusman, M. Dahlan, and F. S. Hilyana, "Rancang Bangun Prototype Alat Penjemur Pakaian Otomatis Berbasis Arduino Uno,” Simetris J. Tek. Mesin, Elektro dan Ilmu Komput., vol. 9, no. 1, pp. 513-518, 2018.

[2] F. M. Arjitya, "Perancangan Prototipe Jemuran Pakaian Otomatis Berbasis Arduino Mega 2560," 2017.

[3] F. Sholihin, A. Setiyo, and B. Nugroho, "Rancang Bangun Miniatur Jemuran Pakaian Pintar Berbasis Internet of Things," Poros Tek., vol. 9, no. 2, pp. 29-33, 2017.

[4] A. B. Rizkianto, "Kelembaban Menggunakan Metode Pid ( Proportional Integral Derivative )," Fak. Teknol. Dan Inform. Inst. Bisnis Dan Inform. Stikom Jawa Timur, 2019. 